Résumés des conférences et travaux

\title{
Philologie arabe
}

\section{Jean-Charles Ducène}

\section{(2) OpenEdition \\ 1 Journals}

Édition électronique

URL : https://journals.openedition.org/ashp/1926

DOI : $10.4000 /$ ashp. 1926

ISSN : 1969-6310

Éditeur

Publications de l'École Pratique des Hautes Études

\section{Édition imprimée}

Date de publication : 1 septembre 2017

Pagination : $38-41$

ISSN : 0766-0677

\section{Référence électronique}

Jean-Charles Ducène, "Philologie arabe », Annuaire de l'École pratique des hautes études (EPHE), Section des sciences historiques et philologiques [En ligne], 148 | 2017, mis en ligne le 21 septembre 2017, consulté le 06 juillet 2021. URL : http://journals.openedition.org/ashp/1926 ; DOI : https://doi.org/ 10.4000/ashp. 1926 


\title{
PHILOLOGIE ARABE
}

\author{
Directeur d'études : M. Jean-Charles DucÈnE
}

Programme de l'année 2015-2016 : I. Question de lexicographie arabe médiévale. — II. Nature, environnement et représentation du monde.

La première partie de la conférence a abordé la lexicographie en mettant en perspective les instruments de travail à notre disposition, anciens et modernes, ainsi que leurs limites. Pour illustrer leur emploi, nous avons fait la lecture de deux passages extraits du Ğawāhir al- 'uqūd wa-mu'ìn al-quḍat wa-l-muwaqqi 'ìn wa-l-šshū $d^{1} \mathrm{du}$ juriste šāfi īte al-Asyūṭ̂̄ (né en 813/1410) portant sur la désignation des bateaux et leur gréement. Comme ces textes étaient des exemples de contrats à rédiger lors de la prise en location de bateaux, nous étions certains d'avoir un vocabulaire documentaire et non littéraire, en usage en Égypte au XV $\mathrm{V}^{\mathrm{e}}$ siècle. Al-Asyūṭī insiste d'ailleurs sur le fait que ces noms doivent être indiqués sur les contrats « selon l'usage particulier (iștilāhh) des gens de la mer ». Des quinze noms qu'il donne pour désigner des types d'embarcations spécifiques, douze ont pu être plus ou moins identifiés en utilisant les dictionnaires classiques mais surtout les lexiques spécialisés. Il est apparu que les spécificités de ce vocabulaire technique avaient été, bien entendu, négligées par les lexicographes médiévaux. Les noms étaient les suivants : al-bāt comme butsa « espèce de navire » que l'on retrouve aussi chez Blachère alors que le dialecte égyptien a bațīs « large poutre faisant le tour du plat-bord sur un bateau du Nil et sur laquelle on peut marcher ${ }^{3} » ;$ al-darmūna du grec $\delta \rho \circ \mu \omega v i o v^{4}$ «barge, petite embarcation »; al- 'aqaba « sorte de grandes barques » en Égypte (Dozy); al-qiyāsiya « cayasse » (Dozy), « barque qu'on emploie à la navigation pendant les basses eaux, elles sont plates et pesantes », le dialecte égyptien a gayyaasa « sorte de grand bateau avec une haute proue ${ }^{5} » ;$ al-ḥarrāqa « brûlot, navire à incendier » ou « navire de plaisance avec un pavillon pour se promener sur les fleuves de Mésopotamie ou le Nil »; $a l-s ̌ a h t u \bar{r}$ « barque, grand bateau » ou « petit bâtiment avec un seul mât au milieu »; al-zawraq qui, dans le Qāmūs al-muhìț, racine ZRQ, est simplement défini comme safina șaḡìra; al- 'āmma « radeau de rivière ou de mer » selon Agius ${ }^{6}$; et falūka $a^{7}, \mathrm{pl}$.

1. Al-Asyūṭī, Ğawāhir al-'uqūd wa-mu'īn al-quḍāt wa-1-muwaqqi'īn wa-1-šuhūd, Beyrouth, 1417/1996, 2 vol. I, p. 78 et p. 233.

2. R. Dozy, Supplément aux dictionnaires arabes, Leyde, 1881, s.v.; R. Blachère, M. Chouèmi,et C. Denizeau, Al-Kāmil. Dictionnaire arabe-francçais-anglais (Langue classique et moderne), Paris, 1967, p. 675.

3. El-Said Badawi et M. Hinds, A dictionary of Egyptian Arabic, Beyrouth, 1986, p. 84.

4. E. A. Sophocles, Greek Lexicon of the Roman and Byzantine Period, 2 vol., Cambridge, 1914, réimpr. New York, 1943, p. 396; R. Dozy, op. cit., s.v.

5. El-Said Badawi et M. Hinds, op. cit., p. 726.

6. D. A. Agius, Classical ships of Islam, Leyde, 2014, p. 399.

7. J.-C. Rolland, Étymologie arabe, Paris, 2015, p. 143, pour les diverses étymologies proposées. 
falā'ik « chaloupe » (Dozy). En outre, trois termes avaient été plus spécifiquement décrits par al-Asyūṭ̂i, à savoir :

— $a l-s ̌ \bar{s} \bar{n} \bar{\imath}$ : une "galère » selon Dozy et Agius ${ }^{8}$, qui reçoit ici une description. Il s'agit d'un « [bateau] fin de la quille (musannam?) du bas, effilé de la proue et de la poupe, dont la partie inférieure est dénuée de surcharge, recouvert de planches pour la manœuvre (mu'átila) des rames; il possède une ancre, des tentes, des équipements suspendus, mais il est sans mât ni voile ».

— al-kaka : «Bateau large du bas et du haut, à la proue et à la poupe effilées, large; il possède plusieurs ponts. Le pont inférieur est destiné au fer, au coton (quțn) ${ }^{9}$ de calfatage (ou fil à voile), aux bagages (ou aux charges, at $\underline{a} q \bar{a} l$ ); le deuxième est pour les femmes, les concubines, les esclaves; et le pont supérieur pour les hommes. Sa partie supérieure comprend un ou deux mâts (șầrin, pour șāriya), une ou deux voiles (qil'), une ou deux ancres (sg. mirsāh), des cordes, câbles et un réservoir (ṣahrīğ) pour l'eau douce. »

— al-qaț'a : une "galère » chez Dozy, qui est ici décrite comme « [bateau] plus grand que la kaka. La partie basse et la partie haute sont très larges, comprenant plusieurs ponts dans les parties inférieure et supérieure. Il est doté de lucarnes (sg. rawšan, mot persan ${ }^{10}$ ) gillagées de bois (mušaqqafa), madhūna (?) avec les fenêtres supérieures et donnant sur la mer. Il a des citernes, des fours et des latrines (sg. murtafaqa). Le plancher est recouvert de terre pour la culture de légumes; il possède des mâts, des voiles et des ancres, mais il n'a pas de rames. Si un très grand nombre de personnes se réunissait pour le mettre en mouvement avec des rames, elles en seraient incapables! Il ne cingle qu'avec la volonté de Dieu qui lui offre un vent fort. »

L'exercice suivant a porté sur le vocabulaire lié au textile donné par Ğa'far ibn 'Alī al-Dimašqī (XI'-XII ${ }^{\mathrm{e}}$ siècle) dans son K. al-išāra ilā mahāasin al-tiğāara ${ }^{11}$.

La partie ectodique a d'abord été occupée par l'édition de passages extraits du ta'rīh de l'auteur égyptien melkite Abū l-Makārim (m. début XIII ${ }^{\mathrm{e}} \mathrm{s}$.) à partir du manuscrit la Bayerishe Staatsbibliothek (cod. Arabe 2570) ${ }^{12} \mathrm{du} \mathrm{XIII}^{\mathrm{e}}$ siècle. En 1984 est parue en Égypte une édition complète de l'ouvrage due au père Samuel al-Suryānī ${ }^{13}$, mais qui d'un point de vue philologique est à revoir. Il apparaît ainsi que le Ta'rīh d'Abū 1-Makārim n'est pas une chronique mais plutôt une topographie historique qui mentionne les lieux en Égypte, en Méditerranée et en Inde où le christianisme s'est implanté. D'ailleurs, depuis la publication du père Samuel des études

8. R. Dozy, op. cit., s.v.; D. Aegius, op. cit., p. 20.

9. H. Grosset-Grange, Glossaire nautique arabe ancien et moderne, Paris, 1993, p. 63.

10. J.-C. Rolland, op. cit., p. 98.

11. Ğa'far ibn 'Alī al-Dimašqī, K. al-išāra ilā mahāasin al-tiğāra, Beyrouth, 1999, p. 38-41.

12. U. Zanetti, «Abū l-Makārim et Abū Șāliḥ », Bulletin de la société d'archéologie copte, 34 (1985), p. 85-138; J. Den Heijer, «The composition of the History of the Churches and Monasteries in Egypt - some preliminary remarks », dans Acts of the Fifth International Congress of the Coptic Studies, Washington 12-15 August 1992, Johnson, D. (éd.), vol. 2, $1^{\text {re }}$ partie, Rome, 1993, p. 209-219.

13. Șamū'îl, Ta'rīh Abū l-Makārim, s.l., s.d., 4 vol. 
particulières concernant le mont Sinaï ${ }^{14}$, Alexandrie ${ }^{15}$, Édesse ${ }^{16}$ ou encore Antioche ${ }^{17}$ ont été publiées. Il en ressort que l'auteur a réalisé un ouvrage de compilation mais en ayant à sa disposition des sources d'époques diverses et de valeur historique hétérogène, le récit historique côtoie ainsi la légende et l'hagiographie. Nous nous sommes attaché à l'édition de la notice consacrée à Constantinople, f. 171-180 du manuscrit. Cette notice se situe entre celle d'Éphèse et celle de Rome. Une fois établi, l'analyse du texte a montré que quoique la notice d'Abū l-Makārim manque de cohérence, elle est riche d'une information qui reflète les intérêts de l'auteur et sans doute de l'église melkite d'Égypte du début du XIII ${ }^{\mathrm{e}}$ siècle. Constantinople apparaît ainsi aux yeux d'Abū l-Makārim comme une ville où s'incarne le pouvoir byzantin et ceci depuis Constantin, bien que le texte en l'état témoignent que les Francs viennent de conquérir et de piller la ville, et y exercent encore le pouvoir. Ainsi, aux folios 172r$172 \mathrm{v}$, on lit :

« En l'an 920 de l'ère des Martyrs (soit 1204 apr. J.-C.), les Francs conquirent la ville et s'en emparèrent. Elle est entre leurs mains. Le patriarche melkite Nicolas, lors de son ordination en Égypte, à Alexandrie, n'a pu se rendre à Constantinople, à l'habitude de ses prédécesseurs. Les Francs pillèrent et ravagèrent la ville. Ils firent parvenir à Alexandrie des instruments, des ustensiles, des vêtements, des icônes dorées magnifiquement réalisées ainsi que de la vaisselle d'église, de grandes quantités d'or et d'argent. Tout cela arriva sous le règne d'al-'Ādil (m. 1218). Ils en vendirent beaucoup. Ils l'échangèrent aussi contre des biens qu'ils avaient choisis. Ils en remplirent des bateaux. On transporta, à la fin de l'écriture [de ces lignes] en 925 de l'ère des Martyrs (soit 1209 apr. J.-C.), du marbre coloré. La ville est jusqu'à cette date aux mains des Francs. L'empereur byzantin n'y a ni pouvoir, ni mot à dire, ni ordre ni interdit [à prononcer]. Les commerçants s'y rendent puis reviennent au poste frontière d'Alexandrie, comme d'habitude. Les Francs ont dévasté la ville [de Constantinople] comme cela ne s'était jamais vu. » Cet aspect contemporain est cependant noyé dans l'évocation de rituels impériaux byzantins. L'empereur nous est montré couronné à Sainte-Sophie et fêtant Pâque avec éclat. Quant à la ville de Constantinople, c'est avant tout comme ville chrétienne qu'elle apparaît par sa fondation, par

14. J.-M. Mouton et A. Popescu-Belis, « Une description du monastère Sainte-Catherine du Sinaï au XII $^{\mathrm{e}}$ siècle : le manuscrit d'Abū 1-Makārim », Arabica, LIII, 1 (2006), p. 1-53.

15. M. Martin, «Le Delta chrétien à la fin du XII ${ }^{\mathrm{e}}$ s. ", Orientalia Christiana Periodica, 63 (1997), p. 181199 et « Alexandrie chrétienne à la fin du XII ${ }^{\mathrm{e}}$ siècle d'après Abū l-Makārim », dans E. Dècobert (éd.), Alexandrie médiévale, Le Caire, 1998, p. 45-49; N. Y. Youhanna Nessim, « Melkites in Egypt according to Abū l-Makārim », Parole de l'Orient, 34 (2009), p. 251-279 et «A contribution to the episcopal list of the Coptic Church », Parole de l'Orient, 37 (2012), p. 1-28.

16. K. Ciggaar et C. Ten Hacken, « The description of Edessa in Abu al-Makarim's History of the Churches and Monasteries of Egypt and some Neighbouring Countries », dans K. Ciggaar et V. van Aalst, (éd.), East and West in the Medieval Eastern Mediterranean, II. Antioch from the Byzantine Reconquest until the end of the Crusader Principality, Louvain, 2013, p. 201-218.

17. C. Ten Hacken, « The description of Antioch in Abū al-Makārim's History of the churches and monasteries of Egypt and some neighbouring countries », dans K. Ciggaar et D. Metcalf (dir.), East and West in the medieval eastern mediterranean, I. Antioch from the Byzantine reconquest until the end of the crusader principality, Louvain, 2006, p. 185-216. 
ses églises et ses monastères, ainsi que par la présence de nombreuses reliques ${ }^{18}$. Grammaticalement, si la langue appartient au moyen arabe, d'un point de vue lexicale on trouve plusieurs emprunts au grec byzantin, comme al-anbal pour l'ambon,

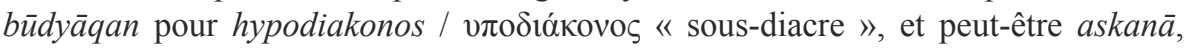
pour $\sigma \kappa \eta v \eta$, « tabernacle, scène ».

Nous avons ensuite repris l'édition de la Risāla fì tab`al-Iskandariyya («Épitre sur la nature d'Alexandrie ») du médecin juif Ibn Ğumay“ (m. 594/1198) commencée il y a trois ans. Nous l'avons continuée à partir du dixième chapitre "Sur quoi le médecin doit-il s'appuyer dans le traitement des maladies de la population d'Alexandrie » et nous l'avons terminée par le onzième et dernier chapitre qui était en réalité la conclusion de l'opuscule.

18. Ce texte paraîtra dans Van Steenbergen et K. D’Hulster (éd.), Egypt and Syria in the Fatimid, Ayyubid and Mamluk Eras IX, Louvain. 